\title{
Factors to consider in the application of Agile Methodologies for teaching and learning English grammar in Higher Education
}

\author{
Juan Habib Bendeck Soto*, Diana Carolina Toro Ocampo** \\ ${ }^{*}$ Foreign Languages and Cultures, Uniremington University \\ ** Foreign Languages and Cultures, Uniremington University \\ DOI: 10.29322/IJSRP.11.08.2021.p11665 \\ http://dx.doi.org/10.29322/IJSRP.11.08.2021.p11665
}

\begin{abstract}
This paper is related to the application of the agile methodologies and learning sprints in a private university in Colombia, considering its use for teaching and learning grammar in English as a Foreign Language (EFL), allowing students to strengthen teamwork, develop autonomy to work with other peers through the designation of specific roles based on these methodologies, and learn English grammar differently. This study considered a qualitative approach and was applied in English courses from regular semesters, incorporating different topics from the current English grammar curriculum, so students could develop them with other peers from different faculties. The results and findings described that 108 students were strongly identified with applying the different methodologies in a 3-month period basis during a semester, so that it could be applied in other core topics of their careers, considering advantages and disadvantages these methodologies could derive in. It was also stated that implementing these learning methodologies requires planning, organization and motivation to students for developing and recognizing their academic skills to participate actively; besides, the obtained findings proved that teachers or professors might find hinders in giving dynamism to the regular functioning of the methodologies, more learning and communication effectiveness between students, and more collaborative work between peers within the classroom.
\end{abstract}

Index Terms- Agile learning; Colombia; EFL; higher education; learning sprint; teamwork.

\section{INTRODUCTION}

$\mathrm{T}$ Agile methodologies are a set of concepts used by software enterprises and other production sectors to develop teamwork and collaborative work among the members of a team to fulfill a specific project. It considers several iterations (sprints) to develop each part of the project to work together, providing cooperation among team members which improves communication and interaction; besides, it enhances their individual talents in teams to reach common goals efficiently [13].

Since Agile methodologies have proved to be helpful in the management of engineering teams and software projects, the perceptions of different researchers (Breakspear as the founder
(2019), [17]) show that it is a proper time to include them and readjust them to an educational environment and this inclusion has changed in current times; for instance, SCRUM (process framework used in business projects to strengthen teamwork in different given trial-and-error tasks) or the Kanban methodology (methodology to visualize the workflow from a process executed by a team in different stages) could be used more often as a way of teaching a specific topic, including the concept of learning sprints [9] in which students, working in teams within short periods, can learn any topic in any subject, including English as a Foreign Language (EFL).

As this concept is not new in engineering environments, the incorporation of Agile methodologies and the learning sprints in the classroom makes teachers consider the possibility of using and setting up new teaching methods which allow richer and much more active learning for students, boarding the concepts of team working and collaborative work as the main principles. Otherwise, teachers must interrogate themselves in their practices to promote an innovative change in the classroom, considering the positive and negative aspects within the process [6], so that it can be more effective and more student-oriented.

The purpose of this study was to explore and implement the application of agile methodologies and learning sprints in the classroom for teaching EFL (English as a Foreign Language) in a private university located in Medellín, Colombia, as an initial and different approach to teaching and learning EFL in higher education, which could provide a better learning praxis to the area. Additionally, this study's main goal is to show the effectiveness and innovation in teaching and learning EFL grammar in the classroom under Agile methodologies, use learning Sprints [9] as one of the main actions to develop different grammar topics, seeing that they have been proven to be effective in teaching other subjects, for instance, Mathematics [18] or main subjects from systems engineering, such as software development or programming language related; among the execution of the study, it was studied the different factors that could facilitate or hinder the application of Agile methodologies in the classroom.

The type of study was given in qualitative research with a phenomenological focus, where the focus was to collect the opinions and perceptions from students who worked under these concepts (learning sprints and agile methodologies), likewise with the evidence of their developed work within these 
methodologies during the classes. Besides, these learning methodologies were applied as an innovative approach in higher education, since elements such as teamwork, collaborative work and EFL learning, some elements are being required to be developed and strengthened in general education nowadays and which require a continuous process in future professionals.

\section{THEORETICAL BACKGROUND}

New literature has been coming up regarding the application of Agile methodologies and learning sprints, and it is getting more interest from teachers to apply these approaches in the classroom, such as the work from [31], [17], [36], [12], [21], [11], and [23]. The study was supported on three key aspects which will be further explained below: Agile in education, Learning Sprints, and the innovational factor in teaching and learning EFL.

\section{The concept of Agile in education}

Agile learning is considered as a practical teaching method where students are called to develop teamwork and critical thinking skills [22] to learn as members of a team, along with the abilities to solve problems and dynamically expand their knowledge; moreover, it gives teams an important role in promoting the equitable distribution of roles and responsibilities, extending the communication among them, and dividing the workload into academic tasks [26]. The relevance of agile learning arises in its implementation as a learning system that can be applied in any subject, in different time frames of an academic period for specific topics, even for a whole subject if desired [1], and the possibility to foment the acquisition of transversal skills so highly required these days [38].

SCRUM framework (not an acronym), created by Ken Schwabber and Jeff Sutherland, is known as an iterative agile methodology for managing product development and teamwork between the members or a team, where they work as a unit to reach a shared goal, and enables teams to self-organize by encouraging physical co-location or close online collaboration of all team members [24]. When we take the concept to an educational environment, there is no difference between applying it for software development or applying it for Math or Foreign languages learning, and that is where the concept of EduSCRUM appears. EduSCRUM is an academic framework taken as an adaptation of SCRUM methodology to education, created and first applied in secondary education in the Netherlands, it can be used in any class context, and it is defined by [15] as a methodology where students can face complex and adaptive problems, while they define learning goals and allow them to work autonomously throughout different educational workflows and learn how to collaborate and self-regulate their collaboration effectively [25] through learning sprints, a concept introduced by Simon Breakspear [8] as an organizational routine that can support the adoption of evidence-informed practices and develop the collective efficacy of teacher teams, defining the learning topics to learn in a specific time for a particular area.

EduScrum manages certain roles, where we have the teacher (Product Owner), a team leader (SCRUM Master), and a threemember team (students). Within each team, each one of the members possesses unique abilities and personal qualities that will determine the team's success. Each team is responsible for its results and the team leader is in charge of promoting collaborative tasks and autonomous work, setting goals and setting the behaviors and attitudes between each member, so it can guarantee success in the established learning goals. Then, in this instance, the teacher becomes Product Owner, providing not only liberty to students to work on the class activities, but also allows him/her to provide feedback when a student needs it; providing advice on the different problems, students might face during the development of the activity [30].

The SCRUM methodology is usually supported by the Kanban methodology, a visual system which defines, improves and manages services that result in new knowledge work [3] that must go through different work stages until obtaining the final product. When both are being used, it enhances not only eduSCRUM but other Agile methodologies [2] as well. What is important in this matter, is that the impact that they could have on subjects different from software development or information systems has not yet been defined [34] when integrating them both; additionally, recognizing that these methods have similarities in operation performance and functionalities to learn content (Agile Learning), making it necessary to consider the learning needs students might have and the learning preferences of the teacher, even when some aspects of the Agile and pedagogical strategies can be used in a traditional or innovative class environment [33]

\section{The process of Teaching and Learning Sprints}

The sprint is a concept from Agile methodologies, which is described as a short repeatable action that can last from one to four weeks, and it is characterized by the consistency in time throughout the development process, has a start and end date, and a new sprint starts after the conclusion of a previous one.

Adapting this concept to a teaching and learning environment, [9] describes teaching sprints (covering the learning sprints among the concept) as a team-based process that activates a continuous development of teacher and students' professional practices and supports the definition of specific areas of student learning to improve. Also, it allows the molding of strategies involving the collection of evidence to check the impact of previously designed learning strategies.

The whole process has been created to be easily adapted by teachers and educational leaders, along with the manageability to be adapted to any academic context, focusing on the specific challenges that the classroom requires. This process consists of three phases:

- Preparation: In this phase, teams employ in a quick chat about what they must do, considering the first steps to follow, setting up the proper strategies to improve within the team, and coming after in-depth research to identify the key concepts of the work to develop.

- Sprint: Phase where students put into practice the knowledge acquired, adjusting the different concepts from each member of the team through short and manageable cycles of teaching/learning in the classroom so that all team members can properly manage the same information and knowledge. This phase can take between 2 to 4 weeks.

- Review: This phase involves the last part of the process, where teachers and students analyze the impact of the collected evidence and pedagogical knowledge. Moreover, 
sharing all the insights from the sprints to the whole classroom.

\section{Innovation in teaching and learning EFL Grammar}

In the current generation, learning English grammar is being measured more in terms of communicative skills rather than the grammatical rules themselves, due to the fact that, even though all skills are important, understanding how to write and how to build sentences is crucial for having proper language For this reason, it is the teachers' responsibility to find different methodologies to explain the different English grammar contents and get students motivated and engaged in the language, because previous experiences has given teachers a lot to learn about teaching these topics using different types of activities and resources without being successful. Therefore, applying innovative components might provide additional learning for seeking success stories within the classroom [10].

The use of Agile methodologies like SCRUM or a Kanban board altogether as an innovative teaching methodology has become a key element within the different traditional teaching methods and

\section{RESEARCH METHOD}

The research method applied to this project was through a qualitative focus. It was required to use a phenomenological and ethnographic approach, starting from a phenomenological point of view to know the experiences lived by students regarding the application of these new teaching and learning methodologies [37].

\section{Data collection}

For the data collection in the study, it was necessary to apply three instruments organized by parts: in the first part, the semi structured surveys were piloted by three students, in order to understand each one of the statements given to answer; the participant observation was piloted in the classroom, letting students know that they were part of a research study; and a document analysis, where the pilot was executed by the researchers, where they reading and analyzing the different curricula in the Foreign Languages and Cultures.

After the development of the study, students completed an online semi-structured survey with 7 closed-ended and 3 open-ended questions, which evaluated the different perceptions and feelings of agile learning, knowing the sensation of implementing this methodology over traditional EFL learning methods. The survey included definitions of agile learning and the definitions of the different SCRUM roles along with identifying the key success factors for this methodology and included open and closed-ended components (See Figure 1: Survey).

Along with this, participant observation was applied in every class where the methodologies were used, in order to check the students' perceptions and the different gestures and speaking practices throughout the application of the study. This data gathering method was chosen because this enabled researchers to learn more about the different activities students participate and integrate within the activities as well and provides a wide context for the development of guides useful to determine the sample of students and the types of questions to apply in the survey or questionnaire [16]. its implementation of Agile automatically fit for courses that include a final project [33]; however, adjusted to teaching and learning EFL can provide a special impact on students, considering that the focus of learning a second language should improve academic and technical learners' skills [4] and mainly, the strengthening of knowledge in English grammar that can keep them interested in the language domain, but also gives the teacher the spirit of creativity in this field up to the point that it can expand it to its fullest potential (Ávila, 2015).

Subsequently, the current educational reality calls learners and educators for new roles, to increase the creativity and innovation within a classroom. In the case of implementing Agile methodologies, it can be taken as an innovative method for teaching and learning EFL skills in the classroom, thus implementing new teaching methods for learning a new language allow teachers to move from being a knowledge transmitter to become a facilitator and a guide to students in their learning process, then students can now become more self-directed and active in their learning processes [29].

Finally, a document analysis was performed, taking the syllabus from levels 1, 2 and 3. From this process, it had to be considered the topics, the level of difficulty, and the purpose of choosing the topics to work on for each level.

\section{Context}

This study was generated to promote the implementation of new teaching methodologies within the classroom to learn English as a foreign language as well as to start promoting teamwork and collaborative work within the different faculties of the University (Medicine, Veterinary, Law, Engineering). Besides, the study was considered pertinent to evaluate different follow-up activities within the regular curricular topics, so that students could not only know the main concepts of agile methodologies but also how they are used in real life and how they can be used inside the university.

These methodologies have been implemented during the last three out 4 semesters ( 3 times per semester) by three teachers in the English department, who were led by one of them who was in charge of explaining the operation of the methodologies, how to implement them in the classroom and how to collect the evidence of this application. Subsequently, it was decided to choose at certain levels such as 1, 2 and 3 to use them with intermediatelevel topics (prepositions,verb tenses and/or the use of adjectives).

\section{Participants}

The population chosen was 108 students who belonged to each regular course of the researchers, where either their English level or career faculty was not important for the sample, and whose age ranges were between 17 and 50 years. The characteristics of the population managed diverse qualities, based on their knowledge (from a basic level (A1) to an advanced level (B2)), their academic performance, so each teacher could designate how the teams would be conformed to develop the designated topic (for this, each teacher chose one B1-B2 student as the leader, and the other three with an A1-A2 level). 


\section{Procedure}

The introductory procedure assigned for this study, considering the class scheduled time, took approximately 1.30 hours to each teacher, given as follows: 15-20 minutes to prepare students, where initially, each teacher gave a brief introduction about this concept of Agile methodologies, how they were used in the current world and which methodologies are the most used; then, a context of these methodologies was given in the learning environment from different areas of knowledge and subsequent, explained the different roles that exist within each of them.

After the explanation, 10 minutes were assigned for teachers to write the names of the members for the selected teams (between 3-9 members is the suggested by the Scrum Guide (2020), whereas all members should manage necessary skills to show a final product, and such number is determined by the needs of the product to hand in). It was decided to work in groups of four, since most of the classrooms had an even number of students, and each group was designated a leader (in this case, the Scrum Master) and designated three other team members responsible for developing each one of the parts of the topics to learn.

Afterward, the teacher (the product owner) drew a matrix or table (similar to a Kanban Board) on a white board, in which he placed the names of the teams, as well as three columns where the tasks were shown to be developed, the ones that were in execution and the tasks that had been completed by each one of them (To do / In Progress / Done).

When all instructions were clear for students, the team leader distributed the topics in three parts, so that each of the team members had to learn each topic well and then be able to explain it to each of the team members; in that way, the whole team could assimilate and understand the topic completely. For this, the teacher assigned one-hour time limit for students to cover the topics, as each team worked and developed their respective part of the topic; while they were working on their respective tasks, each member was moving their post-it stickers on the white board from one column to the other, and the Scrum Master (the team leader) was constantly validating that each member was working on their tasks at the designated times. Meanwhile, the teacher allowed students to surf on the Internet with their mobile devices and computers, so that each member could search and practice the given task and also review what was explained or taught by the other members.

Regarding the role of the Product Owner (the teacher/professor), they were in charge of verifying and ensuring that each student had understood the topic(s) at its fullest while providing advice and supporting each of the teams in any of the topics that had a certain degree of difficulty. As each of the team members was finishing their homework, each of them was moving their post-it stickers to the final column of the Kanban board (DONE); then, after the time expired, the teacher started evaluating the acquired knowledge with each of its team members (including the scrum master).

Finally, when all the teams had already moved their post-it stickers to the DONE column or completed tasks, the teacher stopped the activity and began to assess the knowledge of each of the team members through open-ended questions oriented to the grammar topics assigned (e.g. working with tenses: Where does she work?, What have you learned so far?), or through examples which allowed the validation of the acquired knowledge, not only through speaking questions but also in writing and the other skills (e.g. Complete the following sentences using the correct form of the tense or create sentences using the respective given topic in a real-life context).

After the first time, the methodologies were assigned through the semester, whereas each group knew the dynamics and the procedure to follow.

\section{FINDINGS AND DISCUSSION}

After the application of the given survey for the study, the document analysis and the participant observation, a triangulation process was done to obtain relevant information about the knowledge and impact of the methodologies in the classroom, as well as to discover some of the factors that could hinder or have a negative impact on the implementation and application of these methodologies (See figure 8). This item would give a better view of the aspects to improve in the activity for a future application in the subject and other subjects if the case.

\section{Knowledge and impact of the methodologies}

Based on the obtained results, $67 \%$ of the surveyed students identified the concept of agile methodologies (See figure 1).

Figure 1. Chart related to the knowledge of agile methodologies Before the activity, did you know the concept of agile methodologies?

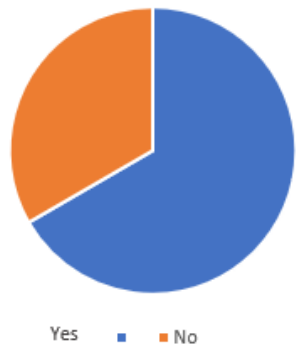

Also, students were able to recognize the fundamentals for developing activities in the classroom using the methodologies, because it offered many advantages in the educational environment that can be taken as a big benefit in experimentation [14] by teachers, and allow others the exploration of different aspects to implement in the classroom (See figure 2).

This determines that students, despite of their study field or career, are in context with the current concepts of Agile methodologies and its different uses and applications, which allows to have a contextualized classroom and students with a basis for working with them, making the dynamics easier for all of the participants involved.

Figure 2. Chart related to the most difficult part of working in teams 
What do you think was the most difficult part of working with peers other than yours? Why?

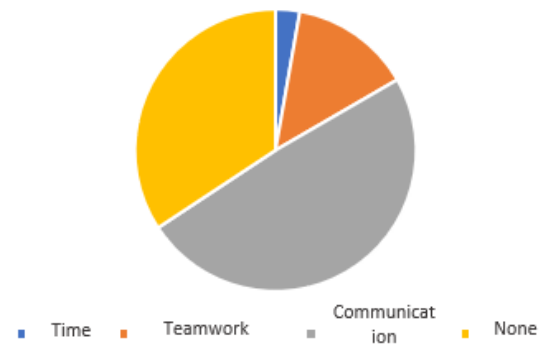

Reviewing the opinion of the students, it was noticed that all of them had a good impression of the application of agile methodologies for learning English as a Foreign language because they were able to see an innovative class and a different way to learn English, which is very difficult to obtain in the institution due to the disavowal or disapproval towards it. Therefore, when innovation is brought to subjects like English as a Foreign language or transversal subjects, students become more motivated and more engaged to develop the activity [6]. (See figure 3).

Based on the results of this question, teamwork is not an easy task to make it work in the classrooms of this generation; however, with good motivation and good engagement, it is possible to organize them or to make them self-organize to work properly for common goals.

Figure 3. Chart related to the relevance of the experience in students

How do you consider your experience working under these methodologies in teaching English?

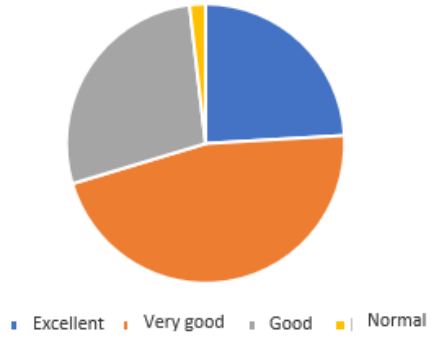

According to the results obtained in this question, the level of acceptance towards these methodologies had a high impact (95 $\%$ ) for learning English and developing an agile learning culture, where learning, growth, challenge, agility, risk-taking, and mistake-making as main aspects must be incorporated [20] and included by students and teachers as well. Also, it was well seen by students that the concept is in context and well-adapted because it promotes simplicity and flexibility to deliver products (learning topics) that are relevant [5] for any subject (See figure 4).

Figure 4. Chart related to the concept of future application of the methodologies in other subjects
Do you think these agile methodologies could apply to other subjects within your career?

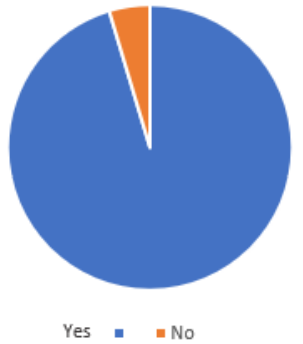

Another important aspect obtained through this question, is that $34 \%$ of students didn't find difficulty working on their respective learning topics and with their respective teams, which means that they were able to develop an understanding about the roles (Team Member and Scrum Master), the collaboration between them facilitates the exchange of ideas and knowledge necessary for the team to come to agreements on the topics involved [32], and most importantly, having clear that trust among academic peers contributes to students' satisfaction [35] without having differences regarding which academic programs they make part of, or even which topic was assigned to work on. Additionally, when the feedback survey was applied, some items were considered to make the methodology better for a future application in the classroom (See figure 5).

Figure 5. Chart related to changes to be applied to make the methodologies more successful

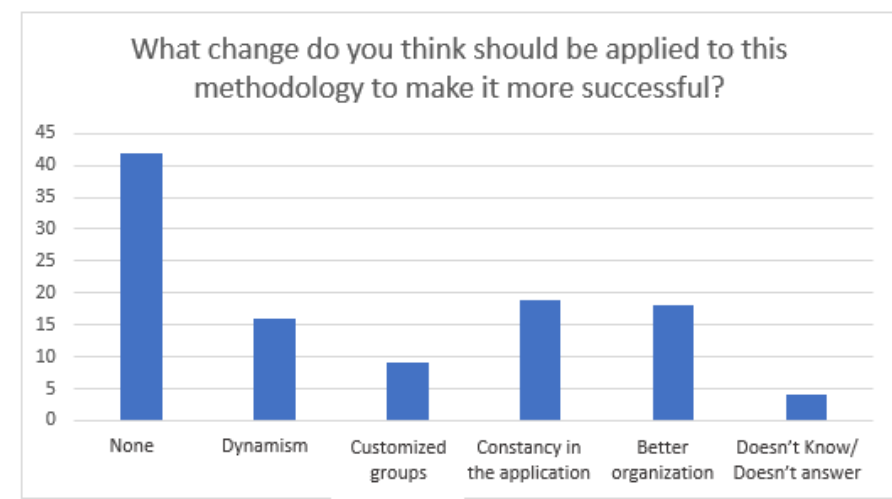

When teams like these can achieve this, then the success of implementing this activity is reflected in their way of working. Next to this, students self-evaluated their performance, a significant aspect due to their self-criticism with all they did, how they learnt the assigned topic and how they worked as a team (See figure 6).

This provides a wide background regarding the feedback to make Agile more effective and more adequate for students to continue working under this modality. Moreover, there is no better feedback to teachers applying these methodologies than students themselves because they're the key to develop more and better practices in the classroom.

Figure 6. Chart related to the self-evaluation of students in the development of the activity 
How would you describe your participation in the development of the assigned theme under agile methodologies?

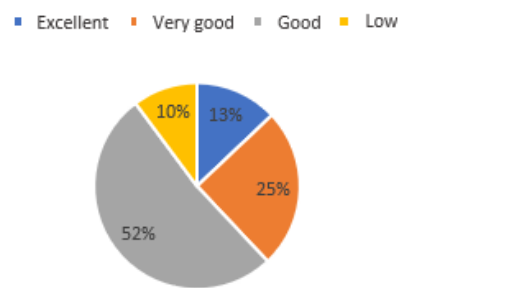

About the logistics and organization, students expressed that the way it was applied by teachers was appropriate and were able to understand all the instructions, the definition of the roles, the Kanban board for assigning tasks to each member of the team and the development of each topic using smart devices (desktop computer, laptops, tablets, mobile phones), along with the respective suggestions on what to improve and to be applied to make it more successful in the classroom (See figure 7).

As a result of the collected answers, it is concluded that, the more tools can be provided to students, the better the dynamics can be for teachers and students as well.

Figure 7. Chart related to changes to be applied to make the methodologies more successful

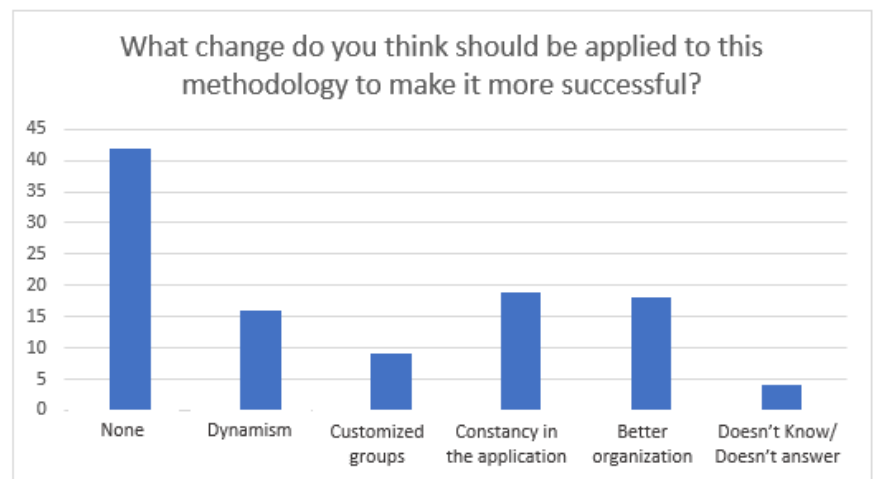

Likewise, this methodology must be at the service of learning and the integral development of the students, adapting always to the educational needs of the same [1], and adjust the necessary changes during the process, knowing that the teacher may make mistakes but most importantly, find them out in time and correct them [5].

\section{Factors that hinder the implementation of Agile}

Figure 8. Chart related to barriers that could hinder the application of methodologies

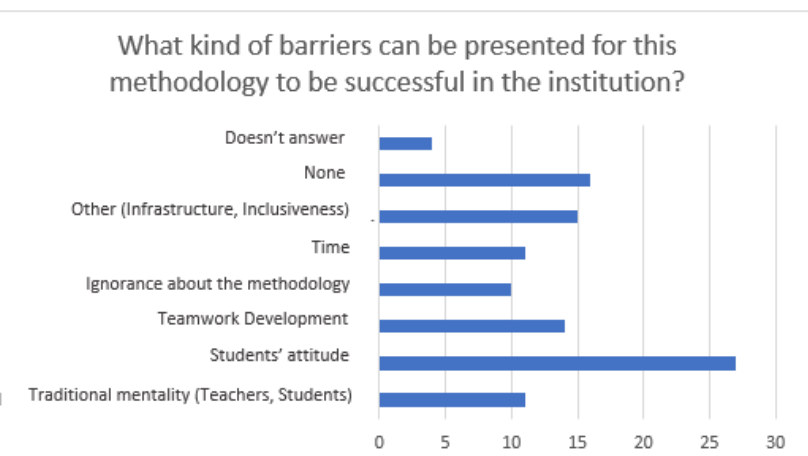

After analyzing the collected data and as part of the findings discovered in this study, three key factors were found during the application of Agile: lack of communication between team members, positive and negative students' attitude towards innovations in the classroom, and lack of leadership. These findings allowed to explore and determine which best practices should have been improved as a result of the activities performed in the classroom and also, to provide feedback to students in their behavioral development through innovative activities.

Table 1. Factors that hinder the application of Agile methodologies in the classroom

\begin{tabular}{|l|l|}
\hline Factor & Definition \\
\hline Lack of communication & $\begin{array}{l}\text { Factor that could hinder the } \\
\text { application of the } \\
\text { methodologies, due to the low } \\
\text { interaction between students } \\
\text { from different faculties and } \\
\text { different egos. }\end{array}$ \\
\hline $\begin{array}{l}\text { Students' attitude towards } \\
\text { innovations }\end{array}$ & $\begin{array}{l}\text { Positive and negative aspects } \\
\text { that influence the application } \\
\text { of innovational activities in } \\
\text { the classroom, due to the } \\
\text { traditionalistic methodologies } \\
\text { and no interest in educational } \\
\text { innovation. }\end{array}$ \\
\hline Lack of leadership & $\begin{array}{l}\text { Role that most of the } \\
\text { participant students do not } \\
\text { have, due to their traditional } \\
\text { mentality of being a regular } \\
\text { worker with no maximum } \\
\text { responsibilities }\end{array}$ \\
\hline
\end{tabular}

Below are explained these factors that hinder the implementation of Agile methodologies:

Lack of communication: After collecting and analyzing the data, it was seen that the lack of communication between the team members and the Scrum Master was a very common aspect that negatively influenced the development of the methodology. The main reason was that, to build trust between team members, it may be difficult to motivate or making students aware of the activity, more specifically in learning environments [28]; additionally, when there is a lack of trust in a team, it leads to the increment of efforts spent by teachers in monitoring and verifying the behaviors of the members [19] that could be 
causing the dysfunctionality and lack of commitment throughout the activity.

On the other hand, the different stated reasons come due to a lack of understanding in the instructions to execute their respective part of the project (in this case, the distribution of the topics to learn), the absence of leadership in students who have excellent knowledge of the topics makes it difficult for the other to follow him/her throughout the activity.

Students' attitude towards innovations: Through the results given from the triangulation, it could be observed that the main cause of why these methodologies cannot be well implemented or well developed, is related to the student's attitude towards a different type of teaching in the classroom.

Based on the experience in the classroom, there was a small group of students who argued even before starting the activity of not working under Agile because they only wanted to have classes with a traditional EFL teaching methodology. This states that students are so used to be greatly dependent on teachers in a way that they fail to develop their skills in English [27], avoiding being the focus of the class and becoming passive agents, which in this generation should be the opposite.

Lack of leadership and time: Considering the different roles, it is relevant to show that from the sample of students taken within the study, assigning the roles within agile methodologies were proportional, in terms of who wanted to be SCRUM Masters or team members, thus there was a lack of leadership in terms of choosing or being assigned the SCRUM master role, and many preferred being a team member because it was considered as the easiest role to play and in which they felt they didn't have too much responsibility to carry, and this was seen in the different scheduled courses given by the University: weekly and weekend courses. Certain behaviors such as confidence and management were detected on the part of the students who attend weekly schedule (Monday to Friday, two times per week), in which the majority of students defined themselves their characteristics and qualities as they were those who possessed the ability to lead teamwork and the ability to learn quickly, which provides an idea of the type of psychological and motivational preparation they have not only to learn a second language but also when they put their role into practice as professionals in the workplace.

On the other hand, it was observed in the students who studied on weekend schedule (once per week), that many of the students lack leadership skills or are afraid to take that role, considering the level of responsibility they must assume for their work team. This is an aspect to consider, especially when we perceive that leadership is everyone's responsibility [7] and when we speak of shared common goals and learning objectives.

\section{CONCLUSIONS}

Based on the obtained results, we can conclude that these methodologies require an important amount of planning time for students to apply them for learning EFL, knowing the population of students considered for this study. Besides being always supported by the teacher, a teacher can provide the necessary support to students with explanations or how to work during a regular learning sprint, and more specifically, when it comes to explaining EFL grammar topics.
Another conclusion from the reported experience and the answers collected throughout the application suggests that learning sprints could be effective and applied to teach in other subjects (See figure 5). Within this process, the use of Agile methodologies and Kanban boards are very useful and dynamic for teaching EFL, because changing the regular educational paradigms about teaching English grammar from a traditional method to an Agile method entails a wide setup process in the design and planning of the classes. However, innovational settings must be well introduced to students, so the basic concepts can be clear and concise to understand and apply later. Considering the results from the application, many of the factors that hinder the application of these methodologies must be prevented from the beginning (establish good communication between students, provide motivation to leadership and innovation in the classroom), so students can value more the dynamics of the activity. Additionally, applying these methodologies along with the learning sprints to promote teamwork and a different way of learning and teaching can transform the pedagogical praxis in higher education, certainly considering that all actors have their roles and allow them to become better in each one of them in a flexible way. Besides, it is important to establish a good organization, the definition of rules, and planning to make this a high-valued methodology in the classroom.

suitable paper for publishing after a thorough analysis of submitted paper. Selected paper get published (online and printed) in their periodicals and get indexed by number of sources.

\section{REFERENCES}

[1] Abadalejo, G., \& Abadalejo, X. (2018, 01 22). Agilizando las las aulas. Guía para implementar la metodología ágil en clase. Metodología Ágil Escuela. https://bit.ly/3pFm5V2.

[2] Ahmad, M. O., Markkula, J., Oivo, M., Kuvaja, P., Ahmad, J., Markkula, M., \& Oivo, P. (2014). Usage of Kanban in Software Companies An empirical study on motivation, benefits and challenges. 9th International Conference on Software Engineering Advances. University of Oulu, Finland. https://bit.ly/3otMQug.

[3] Anderson, D., \& Carmichael, A. (2016). Essential Kanban Condensed. Lean Kanban University Press.

[4] Anil, B. (2017). Applying Innovative Teaching Methods in a Second Language Classroom. International Journal of Research in English Education, 2(2). 1-9. https://doi.org/10.18869/acadpub.ijree.2.2.1

[5] Arimoto, M. M., Barbosa, E. F., \& Barroca, L. (2015). An agile learning design method for open educational resources. 2015 IEEE Frontiers in Education Conference (FIE), 1-9. https://doi.org/10.1109/FIE.2015.

[6] Bendeck Soto, J. (2016). Factores que afectan la implementación de innovaciones en el aula de clase de nivel básico en colombia. Revista Palobra, 16(16), 224-238. https://doi.org/fsh7

[7] Bolden, R., Petrov, G., \& Gosling, J. (2008). Developing collective leadership in higher education. Centre for Leadership Studies, University of Exeter. https://bit.ly/3pqOf6e

[8] Breakspear, S. (2017). Overview - The Learning Sprints Process. Agile Learning from Simon Breakspear Website. https://bit.ly/3cnhZgQ

[9] Breakspear, S. (2019). The Teacher Learning Sprints Process. Simon Breakspear Website. https://bit.ly/3r3CPWE

[10] Carless, D. (2013). Sustainable feedback and the development of student self-evaluative capacities. In Stephen Merry, Margaret Price, David Carless \& Maadlena Taras (Eds.). Reconceptualising feedback in higher education: developing dialogue with students (p. 113). Routledge.

[11] Chun A.H.W. (2004) The Agile Teaching/Learning Methodology and Its eLearning Platform. In: Liu W., Shi Y., Li Q. (eds.) Advances in Web-Based Learning - ICWL 2004. ICWL 2004. Lecture Notes in Computer Science, 
vol 3143. Springer. Berlin, Heidelberg. https://doi.org/10.1007/978-3-54027859-7_2

[12] Ciupe, A., Ionescu, R., Meza, S., \& Orza, B. (2018). Towards Agile Integration within Higher Education: A Systematic Assessment. BrainBroad Research In Artificial Intelligence And Neuroscience. 9(3). 69-87.

[13] Cockburn, A., \& Highsmith, J. (2001). Agile Software Development, the People Factor. Computer, 34(11), 131-133. https://doi.org/10.1109/2.963450

[14] Davey, B., \& Parker, K. (2010). Technology in Education: An Agile Systems Approach. Proceedings of Informing Science \& IT Education Conference, INSITE, 10, 297-306. https://doi.org/10.28945/1253

[15] Delhij, A., van Solingen, R., \& Wijnands, W. (2015, Septiembre). eduScrum Guide "Rules of the game". eduScrum Website. http://eduscrum.nl/en/file/CKFiles/The_eduScrum_Guide_ES_Versie_1.2.p df

[16] DeWalt, K., \& DeWalt, B. (2002). Participant observation: a guide for fieldworkers. Walnut Creek, CA: Altamira Press.

[17] Dewi, D. A., \& Muniandy, M. (2014). The agility of agile methodology for teaching and learning activities. 2014 8th. Malaysian Software Engineering Conference (MySEC), 255-259. https://doi.org/10.1109/MySec.2014.6986024

[18] Duvall, S., Hutchings, D., \& Kleckner, M. (2017). Changing Perceptions of Discrete Mathematics Through Scrum-Based Course Management Practices. Journal of Computing Sciences in Colleges, 33(2), 182-189.

[19] Fransen, J., Kirschner, P. A., \& Erkens, G. (2011). Mediating team effectiveness in the context of collaborative learning: The importance of team and task awareness. Computers in Human Behavior, 27(3), 11031113. https:// doi.org/10.1016/j.chb.2010.05.017

[20] Ghihiuc, I. (2017). 9 Tips for creating an Agile Learning culture. eLearning Industry Website. http://bit.ly/3t4K2aC

[21] González-González, C. S., Toledo-Delgado, P., \& Muñoz-Cruz, V. (2015). Metodologías ágiles centradas en personas para desarrollar software $\begin{array}{lll}\text { educativo. } & \text { DYNA, } & \text { 82(193), }\end{array}$ https://doi.org/10.15446/dyna.v82n193.53495

[22] Lang, G. (2017). Agile Learning: Sprinting Through the Semester. Information Systems Education Journal (ISEDJ), 15(3), 14-20.

[23] López-Alcarria, A.; Olivares-Vicente, A.; Poza-Vilches, F. (2019). A Systematic Review of the Use of Agile Methodologies in Education to Foster Sustainability Competencies. Sustainability. 11(10), 2915. https://doi.org/10.3390/su11102915

[24] Longmuß, J., Höhne, B., Bräutigam, S., Oberländer, A., \& Schindler, F. (2016). Agile learning: Bridging the gap between industry and university A model approach to embedded learning and competence development for the future workforce. 44th SEFI Conference. Tampere, Finland. https://bit.ly/3ajfcCs

[25] Miller, M., \& Hadwin, A. (2015). Scripting and awareness tools for regulating collaborative learning: Changing the landscape of support in CSCL. Computers in Human Behaviour. 52, 573-588. http://doi.org/10.1016/j.chb.2015.01.050
[26] Noguera, I., Guerrero-Roldán, A., \& Masó, R. (2018). Collaborative agile learning in online environments: Strategies for improving team regulation and project management. Computers \& Education, 116, 110-129. http://doi.org/10.1016/j.compedu.2017.09.008

[27] Nur, A., \& Fatema, R. (2016). The factors that affect learner autonomy in learning English as a Foreign Language (EFL) at tertiary level in Bangladesh. ELK Asia Pacific Journal of Social Sciences, 2(4). https://doi.org/10.16962/EAPJSS/issn.2394-9392/2014

[28] Peñarroja, V., Orengo, V., Zornoza, A., \& Hernández, A. (2013). The effects of virtuality level on task-related collaborative behaviors: The mediating role of team trust. Computers in Human Behavior, 29(3), 967974. https://doi.org/10.1016/j.chb.2012.12.020.

[29] Pickering, G., \& Gunashekar, P. (2014). Innovation in English Language Teacher Education. Fourth International Teacher Educator Conference (pp. 223-232). Hyderabad, India: British Council.

[30] Razmov, V. \& Andeerson, R. (2006). Experiences With Agile Teaching In Project Based Courses. Chicago, IL. ASEE Website. https://peer.asee.org/1018

[31] Salza P., Musmarra P., \& Ferrucci F. (2019) Agile Methodologies in Education: A Review. In D. Parsons, K MacCallum (eds.), Agile and Lean Concepts for Teaching and Learning. Springer, Singapore. https://doi.org/10.1007/978-981-13-2751-3_2

[32] Sharan, Y., \& Sharan, S. (1994). Group Investigation in the Cooperative Learning Classroom. In Shlomo Sharam (Ed.), Handbook of Cooperative Learning Method (pp. 97-114). Greenwood Press.

[33] Sharp, J. H., \& Lang, G. (2018). Agile in Teaching and Learning: Conceptual Framework and Research Agenda. Journal of Information Systems Education, 29(2), 45-52.

[34] Tanner, M., \& Dauane, M. (2017). The use of Kanban to alleviate collaboration and communication challenges of global software development. Issues in Informing Science and Information Technology Education, 22, 177-197.

[35] Tseng, H., Wang, C., Ku, H., \& Sun, L. (2009). Key factors in on-line collaboration and their relationship to teamwork satisfaction. The Quarterly Review of Distance Education, 10(2), 195-206.

[36] Twidale, M.B. \& Nichols, D.M. (2013) Agile methods for agile universities. In Besley, T.A.C. \& Peters, M.A. (eds.), Re-imagining the Creative University for the 21 st Century (pp. 27-48). Sense Publishers.

[37] Valenzuela, J., \& Flores, M. (2012). Fundamentos de investigación educativa. Editorial Digital del Tecnológico de Monterrey.

[38] Vergara, D., \& Fernández, P. (2018, 5 29). Metodologías ágiles: de la empresa a la enseñanza. Espacio ENIAC Website. https://bit.ly/3j6gBR2

\section{AUTHORS}

First Author - Juan Habib Bendeck Soto, Master in Education, Uniremington University, juan.bendeck@uniremington.edu.co.

Second Author - Diana Carolina Toro Ocampo, Master in Education, Uniremington University, diana.toro@uniremington.edu.co. 